\title{
ACUTE APPENDICITIS AS A COMPLICATION OF VARICELLA
}

\author{
Zenon Pogorelić1, Mihovil Biočić1, Ivo Jurić1 ${ }^{1}$, Klaudio Pjer Milunović1 ${ }^{\text {, Ivana Mrklić2 }}$ \\ University Hospital Split and Split University School of Medicine, Split, Croatia: Departments of Pediatric Surgery ${ }^{1}$ and \\ Pathology ${ }^{2}$ \\ Summary: Introduction: Obstruction of the appendiceal lumen is the primary cause of appendicitis. The most common \\ causes of luminal obstruction are fecaliths and lymphoid follicle hyperplasia. Additionally, bacterial infections or enteric \\ and systemic viral diseases can cause a reaction of the lymphoid follicle. Case presentation: An 11-year-old boy with active \\ phase of chickenpox presented on our Pediatric surgery emergency department under the impression of acute appendicitis. \\ An appendectomy was performed on the same day. An inflamed and edematous retrocecal appendix was removed during \\ surgery. Histological investigation of the appendix revealed transmural acute inflammation, with diffuse proliferation of \\ inflammatory cells, with characteristic intranuclear inclusion surrounded by a clear halo. The PCR analysis of peripheral \\ blood and appendix tissue specimen revealed positive VZV DNA. Conclusion: We have shown that varicella-zoster virus \\ infection of the appendix is associated with acute appendicitis and possibly also with severity of the disease.
}

Key words: Acute appendicitis; Varicella-zoster virus; Chickenpox; Varicella; Children

\section{Introduction}

Varicella, or chickenpox, is usually a benign, self-limited, primary infection that most commonly affects children aged 3-6 years (11). Primary varicella is caused by the varicella-zoster virus, a herpes virus. Inhalation of virus-infected respiratory secretions or direct contact with skin lesions can produce disease. The usual incubation period is 10-21 days. Viral replication takes place in regional lymph nodes over the next $2-4$ days and is followed by a primary viremia occurring 4-6 days after initial inoculation. The virus then replicates in the liver, spleen, and possibly other organs. This secondary viremia, featuring viral particles being spread to the skin 14-16 days after initial exposure, causes the typical vesicular rash.

Abdominal pain is one of the most common presenting symptoms of children brought to medical attention. Distinguishing appendicitis from other disorders is difficult, particularly in young, preverbal children (1). Acute appendicitis is one of the most common reasons for emergency abdominal surgery in children (10). Incidence of appendicitis gradually rises from birth, peaks in the late teen years, and gradually declines in the geriatric years $(1,10)$.

Obstruction of the appendiceal lumen is the primary cause of appendicitis. Luminal obstruction of the appendiceal lymphoid follicle is mostly caused by fecaliths, carcinoid tumors or foreign bodies (10). Additionally, bacterial infections such as Escherichia coli, Bacteroides fragilis, Yersinia, Salmonella, or Shigella, parasitic infestations such as Entamoeba histolytica, or enteric and systemic viral diseases such as Epstein-Barr virus, measles virus, adenovirus and cytomegalovirus infection, can cause a reaction of the lymphoid follicle $(3,4,6,9)$.

\section{Case report}

A 11-year-old boy with active phase of previously diagnosed chickenpox presented on our Pediatric surgery emergency department with a 24-hour history of nausea and vomiting associated with right lower quadrant abdominal pain. His temperature on admission was $38.6^{\circ} \mathrm{C}$. Characteristic skin lesions in different stages of development (macular, papular, vesicular or pustular) were noted on his face, trunk, and proximal upper extremities.

Abdominal examination revealed right lower quadrant tenderness with guarding and rebound. The patient's white blood cell count was $14.96 \times 10^{9} / \mathrm{L}$ (normal range, children $8-18$ years; $4.4-11.6 \times 10^{9} / \mathrm{L}$ ) with segmented neutrophils, 78.3\%; lymphocytes, $13.7 \%$; and monocytes, $7.5 \%$. $\mathrm{C}$ reactive protein count was $26.41 \mathrm{MG} / \mathrm{DL}$ (normal range; 0-5 MG/DL). All other laboratory studies showed normal values.

Under the impression of acute appendicitis, an appendectomy was performed on the same day. An inflamed and edematous retrocecal appendix was removed during surgery. After the operation, the patient was treated on a pediatric surgical ward. The patient made rapid recovery and was discharged on the fifth postoperative day.

On gross examination the appendix was edematous, with mild serosal congestion. There were no fecalith detected. Histological investigation of the appendix revealed 
transmural acute inflammation, with diffuse proliferation of lymphocytes and inflammatory cells (Fig. 1). Some of the cells were multinucleated and have a characteristic intranuclear inclusion surrounded by a clear halo (Fig. 2).

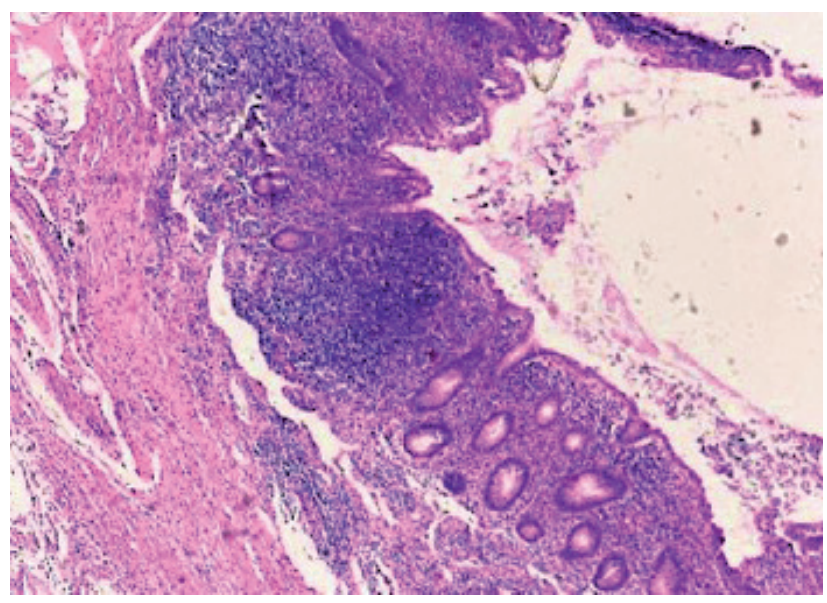

Fig. 1: Histological investigation of the appendix. Transmural acute inflammation, with diffuse proliferation of lymphocytes and inflammatory cells $(\mathrm{H} \& \mathrm{E} \times 40)$.

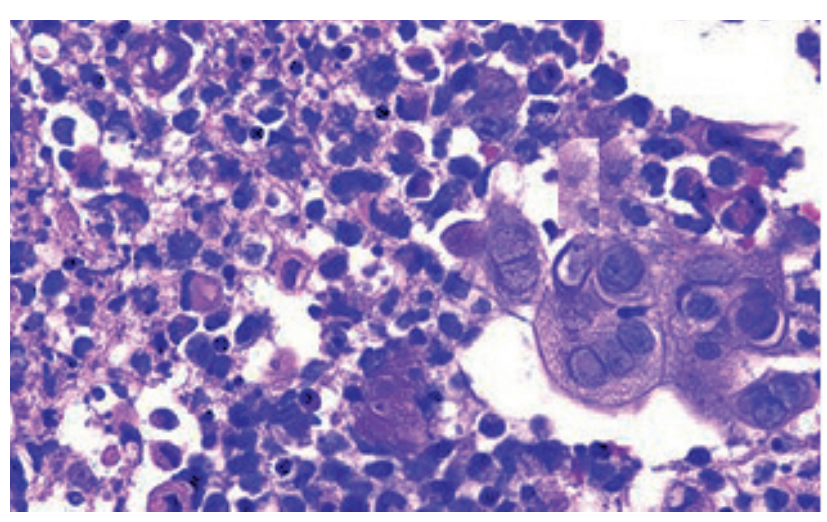

Fig. 2: Multinucleated cells with a characteristic intranuclear inclusion surrounded by a clear halo $(\mathrm{H} \& \mathrm{E} \times 200)$.

The PCR analysis of peripheral blood and appendix tissue specimen revealed positive VZV DNA.

\section{Discussion}

Obstruction of the appendiceal lumen usually precipitates appendicitis. The most common causes of luminal obstruction are fecaliths and lymphoid follicle hyperplasia. Fecaliths form when calcium salts and fecal debris become layered around a nidus of inspissated fecal material located within the appendix (1). Obstruction of the appendiceal lumen has less commonly been associated with parasites or foreign material, tuberculosis, and tumors
$(1,10)$. Lymphoid hyperplasia is associated with a variety of inflammatory and infectious disorders including Crohn disease, gastroenteritis, amebiasis, respiratory adenovirus infections, cytomegalovirus, measles, and mononucleosis $(4,6,7,9)$.

Herpes viruses are ubiquitous pathogens in children, remaining quiescent after an active infection. Herpes viruses are a diverse family of large DNA viruses, all of which have the capacity to establish lifelong latent infections (7). Primary infection with many of these viruses is common during childhood. However, their role in acute appendicitis is poorly understood.

Katzoli et al. applied PCR to detect herpes virus DNA in 38 children who underwent an appendectomy. CMV was the most frequently detected virus, followed by HHV-6, EBV and HSV-1. None of the samples examined were HSV-2, VZV or HHV-7-positive. They concluded that possible viral infection or reactivation can be associated with childhood (7).

In terms of viruses appendicitis the literature is generally restricted to case studies, implicating viruses such as measles, adenovirus or cytomegalovirus $(4,6,9)$. Acute appendicitis has been reported in the setting of CMV reactivation or acute CMV infection in adult patients with AIDS (6).

In immunocompetent children, complications of chickenpox are rare. The most common complication is scarring and may be associated with staphylococcal or streptococcal infections from scratching. Neurologic complications, myocarditis, glomerulonephritis, pancreatitis, Henoch-Schönlein purpura, orchitis, arthritis, osteomyelitis, optic neuritis, iritis, and keratitis are rare (11). Varicella pneumonia is a complication usually of adult varicella and occurs in $1: 400$ cases (11).

There are just few reports in literature of acute appendicitis as complication of chickenpox. Košćak reported case of a nine-year-old girl with an acute perforated appendicitis, which developed as a complication of varicella (8). Camens reported a case of chickenpox encephalitis complicated by acute appendicitis and peritonitis with recovery (2). Harvanek et al. reported a group of 4 children with a chickenpox and acute perforated appendicitis and peritonitis (5). In these reports there was no PCR evidence or pathological evidence of VZV in appendix tissue, and here we describe, to our knowledge, the first case of chickenpox related appendicitis confirmed by PCR and histology.

\section{Conclusion}

In summary, we have shown that varicella-zoster virus infection of the appendix is associated with acute appendicitis and possibly also with severity of the disease. The exact mechanisms causing activation of varicella-zoster virus in the appendix and whether varicella-zoster virus plays a role in the pathogenesis of acute appendicitis has to be investigated further. 


\section{References}

1. Bundy DG, Byerley JS, Liles EA, Perrin EM, Katznelson J, Rice HE. Does this child have appendicitis? JAMA 2007; 298: 438-451.

2. Camens IM. A case of chicken-pox encephalitis complicated by acute appendicitis and peritonitis with recovery. Med J Aust 1950; 1: 439-440.

3. Dykes EH, Garland IW, Gray GR. Yersinia pseudotuberculosis with inflammation of the appendix: a case report. Scott Med J 1987; 32(3): 82-83.

4. Grynspan D, Rabah R. Adenoviral appendicitis presenting clinically as acute appendicitis. Pediatr Dev Pathol 2008; 11: 138-141.

5. Harvanek K, Chromacak V. Infectious diseases in children complicated byappendicitis. Rozhl Chir 1990; 69: 538-542.

6. Kanafani ZA, Sharara AI, Shabb NS, Kanj SS. Cytomegalovirus appendicitis following acute Epstein-Barr virus infection in an immunocompetent patient. Scand J Infect Dis 2004; 36: 505-506.

7. Katzoli P, Sakellaris G, Ergazaki M, Charissis G, Spandidos DA, Sourvinos G. Detection of herpes viruses in children with acute appendicitis. J Clin Virol 2009; 44: $282-286$.

8. Košćak D. Acute appendicitis as a complication of varicella. Paediatr Croat 2002; 46: 23-26.

9. Paik SY, Oh JT, Choi YJ, Kwon KW, Yang WI. Measles-related appendicitis Arch Pathol Lab Med 2002; 126: 82-84.

10. Perko Z, Bilan K, Pogorelić Z, Družijanić N, Sršen D, Kraljević D, Juričić J, Krnić D. Acute Appendicitis and Ileal Perforation with a Toothpick Treated by Laparoscopy. Coll Anthropol 2008; 32: 307-309.

11. Wutzler P., Knuf M., Liese J. Varicella: efficacy of two-dose vaccination in childhood. Dtsch Arztebl Int 2008; 105: 567-572.

Received: $27 / 12 / 2011$

Accepted in revised form: 23/07/2012

\section{Corresponding author:}

Zenon Pogorelić, M.D., Ph.D., Department of Pediatric Surgery, University Hospital Split, Spinčićeva 1, 21000 Split, Croatia; e-mail: zenon@vip.hr 